\title{
The Content of Experimental Medical Studies and the Relevant Law
}

\author{
Jinguo Wang \\ Department of Urology \\ The First Hospital of Jilin University \\ Changchun, China \\ wangjinguolily@163.com
}

\author{
Na Wang* (corresponding author) \\ Department of Anesthesiology \\ The First Hospital of Jilin University \\ Changchun, China \\ wangna080613@163.com
}

\begin{abstract}
Modern medical instruments and new technologies are widely applied to our medical practices. Along with it, many problems arising associated with medical experimental studies, so it is very necessary to establish a perfect legal system to restrict illegal medical practice and to protect the life and health of subjects. The perfect and mature legal system is also the premise condition for effective protection of the rights and interests of the subjects. Once the subjects' personal injury incidents happen, there are laws to base on for compensation. On the base of the previous literature and the current legislation of other countries and areas, we analyze the status of our country and suggest clarifying responsibilities and improving the compensation efficiency.
\end{abstract}

Keywords-experimental medical studies; system construction; law; compensation

\section{INTRODUCTION}

Because of the medical technology industry has the characteristics of high returns, priority to the development of medical technology can promote the development of national economy and the high returns constitute the power source of accelerating the industrialization process. Inducing factors of accelerating and new medical technology industrialization process is the fundamental interests of the people to the survival and health, the medical technology industry became the various countries' demand structure and economic structure continuity and be full of vitality of the emerging industry.

\section{THE PROBLEMS CAUSED BY THE DEVELOPMENT OF MEDICAL NEW TECHNOLOGY AND MEDICATIONS}

The modern medical technology is highly differentiated and highly integrated science and technology, the product of mutual infiltration and cross between disciplines. The connotation of the new technology is developing from the previous chain form into a system of network spatial structure form. Such as organ transplant technology, as complex integrated clinical and basic disciplines, also involves the ethical and legal problems such as the organ donation. At the same time, due to its characteristics across multiple disciplines, both doctors in application of the new technology at the same time, the understanding of the relevant knowledge of its function and effect is not balanced to form the difference of doctor-patient communication. Gene technology, for example, in addition to this discipline content, but also involves a series of ethical, legal and other issues, patients do not understand the inclusion of a series of problems [1].

Modern medicine, new technology applications, organ transplantation, artificial reproductive technology, gene technology, modified new medical technology, such as the risks of the unknown, the types of technology is the most common and controversial. To break points, technical points, indications, safety, efficacy, etc all have no specific strong conclusions which may cause a series of problems, cannot be expected science projects, the ministry of health will be an emergency stop. To the progress of medical science, in the process of the whole human trials using double-blind, placebo experiment, the control group, randomized trials test method on the subjects of the test of the new technology. We know from the concept of medical new technology, new technology means that the unknown and explore. Because for the unknown process, efficacy, safety, the subjects easily cause harm to the body and mind In the process of drug clinical trials, each of the clinical drug research institutions are not less than 3 , from the system point out the new drug clinical trials must be simultaneous, even more than the international center. To ensure the center laboratory and clinical evaluation methods used in the experiment has a uniform data, data query, quality control, transfer and verification procedures also facilitate timely communication experts. Thus it can be seen that drug clinical trial is beneficial to strengthen medical institutions of cooperation with domestic and foreign counterparts, increases the chances of academic exchange, thereby raising the level of scientific research and technology in medical institutions [2].

\section{THE DEFINITION AND SIGNIFICANCE OF EXPERIMENTAL MEDICAL STUDIES}

In recent years, evidence-based medicine is developing fast, because of an objective and sufficient scientific basis to judge the characteristics of the standard, make medicine is medical model from experience to evidence-based medicine pattern transformation. In the whole process of drug clinical trials, large sample randomized controlled clinical trial is a good practice of evidence-based medicine, and drug adverse reactions to judgment is a good reflection of evidence-based medicine. Therefore, may say, drug clinical trial promoted the traditional medicine pattern to the evidence-based medicine pattern transformation. 
Research institution for scientific research project, can send special supervisors to inform the field monitoring work. Monitor the researchers of subjects were told that is easy to understand, test whether the interests and to bear the risk of all concrete and careful teaching subjects, whether the test fee, test subjects can quit at any time without discrimination, damage compensation, in the process of the test subjects can contact test head and their contact information. Ethical review committee is for the implementation of informed consent which is judged by the signing of informed consent. And according to the analysis of the actual situation can expand the scope of the supervision function of ethical review committee, specific to the informed consent prior to supervise, and subjects signed informed consent form of research institutions in particular, the researchers fulfill their obligation to inform the process [3]. Before signing the informed consent personally asked whether real understand told content, whether participants volunteered for the experiment, may at any time to ask questions whether researchers seriously in the inform obligation, whether random inspection in the process of trials researchers informed of the progress of subjects to experiment with new information at any time.

Due to the current medical science is developing rapidly, the new experimental medical behavior problems emerge in endlessly, it should be regularly researchers to conduct regular training for the new problem. The researchers adopt the mode of practice of appraisal behavior is to follow the ethical and moral standards. Medical research on the researcher's personal moral quality requirement is very high, and the individual with the moral quality determines its work is reliable, whether to the subjects to the highly responsible attitude. To improve the training content of legal norms, establish specialized training institutions, to increase moral training courses for the researchers. Because of experimental medical behavior risk is extremely high, once a link error, it will produce damage for subjects to health of body and mind, at the same time, the relevant personnel, organization will face bear legal responsibility. So, we should strengthen the legal system education for the researchers. In the training system, strengthen the legal education system, on a regular basis on the investigation to the researchers on the rule of law, to make it according to the provisions of the law of the subjects to inform obligation, the consent of the participants agreed to participate in voluntary testing. All act in strict accordance with the laws and regulations, respect for the subjects' right of informed consent, protect the life and health of the subjects.

\section{SUPERVISION AND MANAGEMENT OF EXPERIMENTAL MEDICAL BEHAVIOR REGULATED BY LAW}

The United States and our country Taiwan area in experimental medical behavior supervision and management law regulations, set up specifically for protection in the perfection of the social status of vulnerable subjects of legal regulations. China's relevant laws and regulations in this respect, the relative lack of rules and regulations, only in the quality control standard for clinical trials of article 15 second regulation: "the subjects of incapacity, if ethics committee agreed in principle, the researchers believe the participants in a test in its own interests, these patients can also enter the test, at the same time should be agreed by the legal guardians and signed and dated." Third point: "children as subjects, the legal guardian of the informed consent should be sought and signed informed consent, when children make the agreed to participate in the decision, also must obtain the consent." And there are no specific program regulations. It can be amended in this respect, increase in children, pregnant women, the disabled, mental disorder, mental patients, the legal protection of vulnerable groups, at the same time increase the legal guardian should strictly abide by the responsibilities and obligations, in supervision procedure, to have children, pregnant women and other disadvantaged groups to participate in scientific research project, should strengthen the examination and supervision of the entire process, damage to, the researchers should supervise the sponsor, research institutions, in accordance with the corresponding compensation, compensation content at the same time for clinical treatment.

\section{COMPENSATION FOR EXPERIMENTAL MEDICAL STUDIES}

Adverse reactions and compensating for experimental medical behavior in our country, emphasize mainly on administrative punishment, in the aspect of civil compensation is not comprehensive, after the damage compensation and the compensation standard, there is no specific rule. If damage, participants were given an appeal, generally carried out in accordance with the "general principles of the civil law" the fair principle of judgement. Conclude on compensation relief mechanism, the United States by the national vaccine injury act established the fund compensation in the form of a vaccine safety and patients. Our country Taiwan area of the relief act, directly to relief the victim. We can draw lessons from the United States, Taiwan's way, to improve the standard of the corresponding compensation remedy, for specific compensation for the damage fact, respectively. Such as healthy subjects and belong to the disadvantaged groups of subjects, should according to different compensation standard for compensation. Because of the particularity of experimental medical behavior, to participate in research projects of the subjects are faced with the unknown risk, China insurance regulation should be increased for the project of ginseng. Through regular proportional deduction involved in the project sponsor, research institutions, the researchers must have money. In determining the subjects of the number of cases at the same time, the sponsor must for the subjects to purchase insurance, such as research subjects of health damage is first by the insurance company for compensation. They can also set up the system of relief fund which can be made by the government departments, the pharmaceutical enterprises and society.

Individual researchers, research institutions, etc are to share. So, to maintain the health damage to get paid in a timely manner, also can reduce the accident of relevant enterprises, research institutes, researchers and the economic burden.

The development of the medical and health undertakings objectively prompted for new drugs, and the constant innovation of technology and equipment. And this kind of continuous innovation, research and development, in accordance with the legal provisions of the state program, such as the incident, on subjects of economic compensation relief. But there are also many irregularities, intentionally or 
knowingly illegal and to study the behavior of the participants create serious damage to health. Many countries will seriously infringes on the life, health, damage the interests of society's illegal human trials for crime behavior rules. According to the behavior of illegal human trials person consequences attitude is different, it can be divided into intentional crime and criminal negligence. Continental law system develops generally on the criminal legislation, as a crime. Britain, the United States, it is defined as tort law system countries, seeking the infringement relief. China's criminal law for this on the one hand, there is no limit to the specific terms and conditions, the existing crimes mainly include: the crime of illegal medical practice, medical accident crime, murder, intentionally wounding, etc. in the event of serious accidents, only in accordance with the prescribed above a certain charges. Can increase in the crime of illegal practice medicine crime of illegal human trials, or alone for human trials to establish terms and conditions [4]. In order to make clear the experimental of criminal law provisions to restrict illegal medical practice, in order to protect the life and health subjects.

Due to the application of scientific research project is more, many of the ethical review committee in China is facing a great intensity of work, formal review process, and in a hurry, and can't really strict implementation review. The government should intensify support for ethical review committee in view of the ethical review committee of independent department, as the commission and the bridge of the health sector. Only increase capital investment, increase financial input, at the same time to ensure the normal operation of ethics committee, improve the ability of censorship. Although part of the legal norms in China to set up the ethical review committee, work standard, content, procedure and so on all have more or less mentioned. But because of the ethical review committee are scattered within the research institutions and different execution work standards, the resulting examination standard is not unified, the problem such as accident responsibility is not unified. Related departments should formulate unified experimental medical behavior aspects of ethical review standards, refinement of ethical review committee work procedures, including: examination content, examination procedures, time limit for project review of specific review points, review, and so on. Because of ethical review body development relatively late in our country, in the personnel composition, review is yet to be perfected. Institutional ethics committee members of the ethics committee established by it department or the agency on the basis of consultation, from biomedical field and management, ethics, law, sociology, etc. are produced in the experts in the field of social science, and should have different gender of members. Ethnic minority areas should be considered members of ethnic minorities.

\section{LEARNING FROM OTHER COUNTRIES AND AREAS}

Can follow the United States and our country Taiwan area of ethical review agency personnel constitute conditions, in addition to professional, professional, and gender have specific requirements, also involves factors such as age, race. At the same time, to perfect the laws and regulations, clear legal responsibility intensifies punishment for lack of fairness, ethical review behavior from institutional constraints. Can draw lessons from the U.S. food and drug administration specification: revocation in violation of the rules and will not change the ethics committee review, and the ethics committee of experimental institutions also need to be punished by the joint of the same, and drug regulatory agency of the test data from revoked the ethical review committee and test units of new drug applications rejected to issue the false opinions, thereby causing serious consequences, the pursuit of the criminal responsibility in accordance with the law [5].

We think that, the use of ethical review double umpire system is the most representative in Taiwan. The human subjects committee organization and practice of medical institution ", human trials after medical institutions human trials committee approved before submitted to the department of health. The department of health examination in two phases: the first stage is expert preliminary examination and review, preliminary examination by the department of health relevant experts or institutions entrusted to provide the preliminary examination opinion, reference and the preliminary examination opinions to the hospital, hospital for preliminary examination opinion or revised plan. Review the trial would apply for hospital proposed by the department of health shows or correction plan, entrust the relevant experts or organizations provide review opinions. The second stage is the medical review committee review, that is, the department of health medical review committee of experts preliminary examination and review, review of human testing plan shall include items, planning of technology security, protection, legitimacy, and any ethical or social subjects controversy and biological safety, etc. In this mode, the commission has played a role of selfdiscipline and have played an important role in information communication improve research level. In the submission and modify the plan at the same time, the applicants and members helped to promote the whole medical exchanges and communication between the improvement of academic level.

Because in our country in recent years the rapid development of society, has become the world's base of numerous clinical trials, many of the first instance available ethical review board test applications, reduce the financial burden of the government administrative departments at the same time also have played an important role in saving resources.

There is no specific regulation, supervision and inspection frequency. And to monitor the process of experimental medical behavior in practice, the more attention to the initial research plan review, for during the process of research involves changes in the plan, modifying, informed consent whether change problems such as lack of necessary attention. After testing scheme through the preliminary examination, lack of necessary follow-up supervision mechanism, and if there are any problems, not the real solution." In this respect we should draw lessons from the United States continue to review" and Taiwan "track review" mechanism, they require the study of approved plans appropriately in the process of scrutiny, the purpose is to be able to timely solve the problems, maintain the rights and interests of the subjects. Mentioned above, our country to monitor the work of the ethical review committee, no specific regulations review content also does not have the corresponding specific supervision rules. For most of the ethics 
committee in our country set up within the agency and thus may result in the examination is owe justice issues, specifically for management department to supervise.

\section{LEGISLATION ASSOCIATED IN OUR COUNTRY}

Supervision contents should also include the number of committee, major, gender, etc. is in line with the requirements whether there is a conflict of interest between members, ethics committee review results in written form, review procedure and records are in accordance with the law.

According to our country "special medical technology grey bed application management regulations (draft)" knows the ministry of health on special medical technology projects include: 1) first introduced from abroad; 2) at first; 3)high risk; 4) has significant influence on social ethics; 5) other need special technology project management. According to the above mentioned, in the actual implementation process, the definition of fuzzy. The definition of new medical technology project should be refined, according to the actual situation and the revision at any time.

\section{CONCLUSIONS}

In order to make clear the experimental of criminal law provisions to restrict illegal medical practice, in order to protect the life and health subjects. Due to the application of scientific research project is more, many of the ethical review committee in China is facing a great intensity of work, formal review process, and in a hurry, really strict implementation review. The government should intensify support for ethical review committee in view of the ethical review committee of independent department, as the commission and the bridge of the health sector. Only increase capital investment, increase financial input, at the same time to ensure the normal operation of ethics committee, improve the ability of censorship. Establish a perfect legal system is very necessary.

\section{REFERENCES}

[1] SA M. McLean. A Patient"s Right to Know:Information Disclosure, the Doctor and the Law. 1989

[2] Mccoid. The Care Required of Medical Practitioners. Vand.L.Rev. 1959

[3] Laurel R. Hanson. Informed Consent and the Scope of a physician"s Duty of Disclosure. North Dakota L. Roy. 2001

[4] A Buchanan. "Medical Paternalism". Philosophy \& Public Affairs. 1979

[5] D Michael Wallach, Steven J. Berry. Informed Consent in Texas: A Proposal for Reasonableness and Predictability. Saint Mary's L.J. 1987. 